\title{
Correction to: How the analysis of transitionary references in knowledge networks and their centrality characteristics helps in understanding the genesis of growing technology areas
}

\author{
Konstantin Fursov ${ }^{1} \cdot$ Alina Kadyrova ${ }^{1}$
}

Published online: 5 June 2018

(C) Akadémiai Kiadó, Budapest, Hungary 2018

\section{Correction to: Scientometrics (2017) 111:1947-1963 https://doi.org/10.1007/s11192-017-2340-z}

In the original publication of the article, the project ID was published incorrectly in the Acknowledgements section. The correct Acknowledgement is given in this correction.

Acknowledgements The research leading to these results was supported by the Ministry of Education and Science of the Russian Federation (Project ID: RFMEFI60216X0017). We thank Prof. Robert Tijssen for his reflections on the initial idea of this paper, Prof. Thomas Thurner and Ms. Ekaterina Dyachenko for the fruitful discussions and two anonymous referees for their critical notes and comments that greatly improved the manuscript.

The original article can be found online at https://doi.org/10.1007/s11192-017-2340-z.

Konstantin Fursov

ksfursov@hse.ru

Alina Kadyrova

akadyrova@hse.ru

1 Institute for Statistical Studies and Economics of Knowledge, National Research University Higher School of Economics, Moscow, Russia 